\title{
Revizyon kalça artroplastisinde kullanılan biyomateryaller
}

\section{Biomaterials used in revision hip arthroplasty}

\author{
Ömer Bozduman¹, Barış Can Kuzuca² \\ 'Samsun Üniversitesi Tıp Fakültesi, Ortopedi ve Travmatoloji Ana Bilim Dalı, Samsun \\ ${ }^{2}$ Ankara Pursaklar Devlet Hastanesi, Ortopedi ve Travmatoloji Kliniği, Ankara
}

\begin{abstract}
Total kalça artroplastisi, kalça eklem hastalıklarında başarı ile uygulanan bir tedavidir. Uzun dönemde en iyi sonuçları alabilmek için, geçmişten günümüze kadar gelişen çeşitli biyomateryaller kullanılmıştır. Metal alaşımları, polimerler, seramikler ve kemik çimentoları geliştirilerek, asetabular ve femoral bölge için en iyi sonuçları almak hedeflenmiştir. Günümüzde hem asetabulum hem de femur için çimentolu ve çimentosuz seçenekler mevcuttur. Revizyon cerrahisinde de kullanılan farklı biyomateryaller mevcuttur.
\end{abstract}

Anahtar sözcükler: total kalça artroplastisi; biyomateryaller; polimerler; seramikler; kemik çimentoları
Total hip arthroplasty is an efficient treatment in hip disorders. In order to obtain the best results in the long term, various biomaterials have been used from the past to the present. It is aimed to get the best results for the acetabular and femoral region by developing metal alloys, polymers, ceramics, and bone cements. Currently, cementless and cemented options are available for both acetabular and femoral recontruction. Different types of biomaterials are also available for revision surgery.

Key words: total hip arthroplasty; biomaterials; polimers; ceramics; bone cements

oluşturmaması önemlidir. Hasta ve cerrahın beklentilerini karşılayacak, maliyeti en uygun ve en sürdürülebilir biyomateryallerin oluşturulması da protez sektör imalatçılarının görevidir. İdeal bir protez, güç kalkanı etkisini önleyebilecek kadar esnek ve sağlam bir stabilite sağlayabilecek kadar sert olmalıdır. Protezlerin yüzeyleri kemik temasından aşınmayacak şekilde dayanıklı olmalıdır. Osteoporotik hastalarda kullanılan kemik çimentosu, boşluk doldurucu etkisi ile alternatif bir tespit yöntemidir. Ancak özellikle asetabular bölgede kullanılan kemik çimentolu tespit yöntemlerinde görülen 'çimento hastalığı'na bağlı lokal lizis ve gevşemeler, alternatif tespit yöntemlerinin geliştirilmesini gerektirmiştir. ${ }^{[1]}$

Çimentosuz protezlerde oluşan gevşemelerin ise kemik ile protez arasındaki fizyolojik olmayan yük dağııımından kaynaklandığı tespit edilmiş ve bu durum 'güç̧ kalkanı etkisi' olarak isimlendirilmiştir. ${ }^{[1]}$ Günümüz teknolojisi, revizyon cerrahisinde biyomateryallerin çıkartılması sonrası tespit edilen kemik defekti miktarına bağlı olarak, asetabular bölgede kafes kullanımından kişiye özel üç boyutlu (3D) kemik yapımına kadar birçok alternatif seçenek içermektedir.

illetişim / Contact: Dr. Öğr. Üyesi Ömer Bozduman • E-posta / E-mail: omerbozduman@gmail.com

ORCID iD: Ömer Bozduman, 0000-0002-3874-633X • Barış Can Kuzuca, 0000-0002-3117-9037 


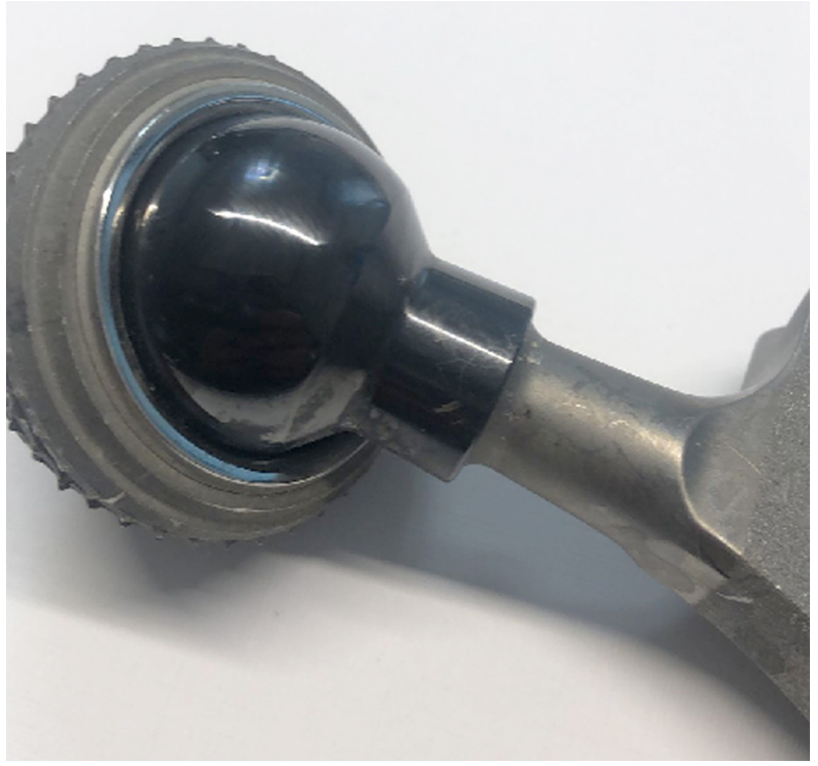

Şekil 1. Çimentosuz metal asetabular kap: Okside zirkonya femoral baş ve çimentosuz femoral stem örneği.

\section{METAL BIYOMATERYALLER}

Femoral ve asetabular bölgelerde kullanılan biyomateryallerin önemli kısmı metal alaşımlardır. Femoral stemler ilk başlarda yalnızca paslanmaz çelikten yapılırken, günümüzde sıklıkla yüzeyine poröz kaplamaya izin veren kobalt-krom bileşimleri kullanılmaktadır. ${ }^{[2,3]}$

Asetabular bölgede ise sıklıkla alümina, zirkonya (Şekil 1) ya da oksinya seramik, politetrafloretilen (PTFE) ya da kobalt-krom kullanılmaktadır. Metalik biyomateryallerin esas sorunu, stres kalkanı etkisi ile kemik protez temasının aşınması sonucunda gevşeme ve oluşan tehlikeli metalik parçacıkların lokal ve sistemik yan etkileridir. ${ }^{[4,5]}$

Mekanik özelliklerinden dolayı titanyum da ortopedi ve travmatoloji alanındaki uygulamalar açısından uygun bir malzemedir, ancak yüzey özelliklerinden dolayı kemiğe tutunmadığı için yalnız başına kullanılamaz; sıklıkla biyo-aktif yüzey elemanları ile hidroksiapatit gibi organik olmayan yüzey kaplamaları ile birlikte kullanılır. ${ }^{[6]}$ Metalik baş ile polimerik insert (PTFE) kullanı$\mathrm{mı}$ en sık tercih edilen kombinasyondur. ${ }^{[7]}$

\section{POLIMERLER}

Polimerler özellikle artroplasti cerrahisinde sıkIıkla kullanılan biyomateryallerdir. Polimerler; dayanıklılığı az olan, erime sıcaklığı düşük olan, iletkenliği zayıf biyo-maddelerdir. Ortopedik olarak kullanılan polimerler; akrilik, naylon, silikon,

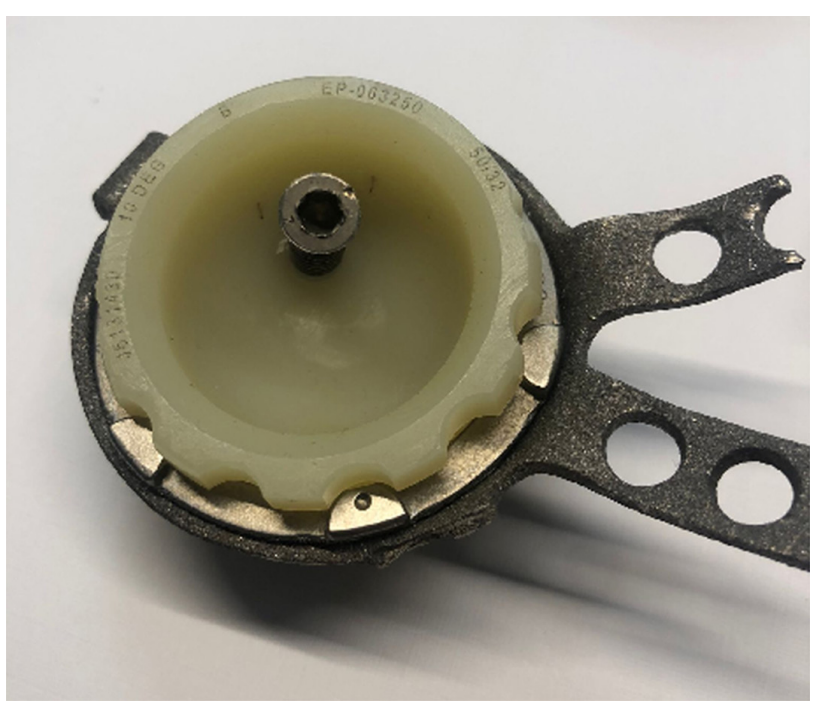

Şekil 2. Anti-protrusio kafes asetabular kap örneği, E vitaminli ultra yüksek molekül ağırlıklı polietilen (UHMWPE) ve revizyon cerrahisinde insert (içlik) çıkartılması için kullanılan vida ile gevşetme uygulaması örneği.

poliüretan, ultra yüksek moleküler ağırlıklı polietilen (UHMWPE) (Şekil 2) ve polipropilendir. ${ }^{[8]}$ Bunların mekanik özellikleri Tablo 1'de gösterilmiştir. ${ }^{[9,10]}$

Günümüzde UHMWPE polimerlerinin asetabular kap uygulaması üstün performans göstermiş olup sıklıkla kullanılmaktadır.

Kemik çimentosu polimetilmetakrilat (PMMA), en sık kullanılan polimerlerdendir. Akrilik kemik çimentosunun, monomer (sıvı) ve polimer (toz) iki komponenti vardır. Sıvı kısımda etkinleştirici bulunur (sıklıkla dimetil-para-toulidin, DMpT). Sıvının içerisinde, ISı veya ışık gibi etkenler nedeniyle bozulmaya karşı, hidrokinon vardır; toz kısımda ise dibenziol peroksit (BPO) içeren PMMA bulunur. Tepkimeyi BPO

Tablo 1. Polimerlerin biyomekanik özellikleri ${ }^{[9,10]}$

\begin{tabular}{lccc}
\hline Materyal & $\begin{array}{c}\text { Sıkıştırılma } \\
\text { direnci (MPa) }\end{array}$ & $\begin{array}{c}\text { Maksimum gerilme } \\
\text { direnci (MPa) }\end{array}$ & $\begin{array}{c}\text { Modülüs } \\
(\mathrm{GPa})\end{array}$ \\
\hline HDPE & 25 & 40 & 1,8 \\
UHMWPE & 28 & 21 & 1 \\
PMMA & 144 & 21 & 4,5 \\
\hline
\end{tabular}

HDPE, yüksek yoğunluklu polietilen; UHMWPE, ultra yüksek molekül ağırlıklı polietilen; PMMA, polimetilmetakrilat; $\mathrm{MPa}$, mega paskal; $\mathrm{GPa}$, giga paskal. 


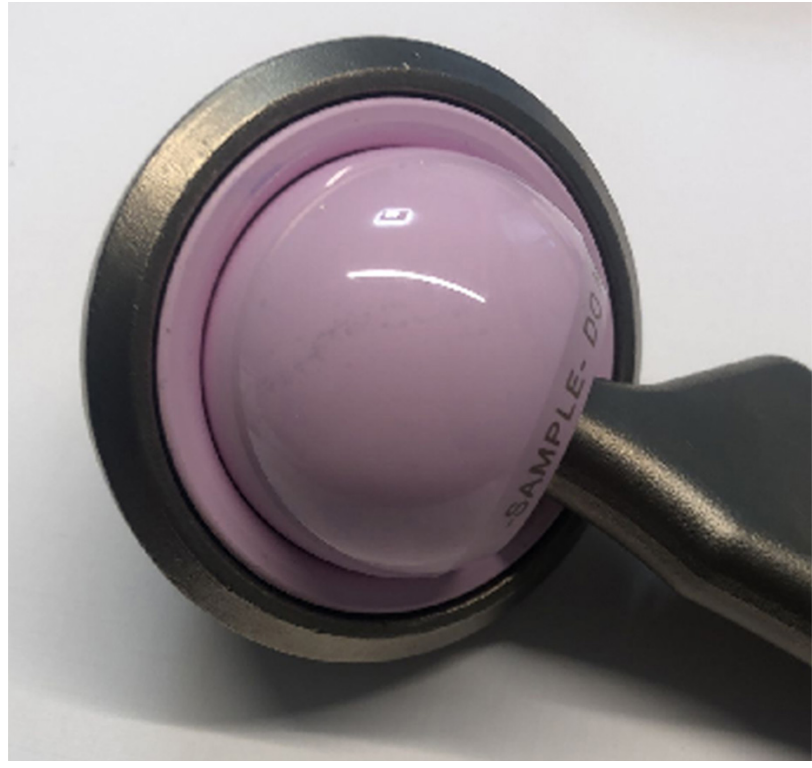

Şekil 3. Çimentosuz metal asetabular kap, seramik insert (içlik) ve seramik femoral baş örneği.

başlatır. Çimentonun radyo-opaklığını, toz kısımda bulunan zirkonyum dioksit ya da baryum sülfat sağlar. Toz ile sıvı komponentler karışınca, polimerizasyon gerçekleşir ve yüksek sıcaklık açığa çıkartan bir tepkime sonucu, yapışkan kıvamlı çimento oluşur. Bu sıcaklık $60^{\circ}-120^{\circ} \mathrm{C}$ arasındadır ve bu nedenle doku nekrozu açısından dikkatli olunmalıdır. ${ }^{[11]}$

\section{SERAMIKLER}

On sekizinci yüzyılın sonlarında diş hekimliğinde kullanılmaya başlanılan seramikler, 1965 yılında alümina seramiklerin total kalça protezi ile artroplasti cerrahisinde de kullanılmaya başlanmıştır. ${ }^{[12]}$

Seramikler, metallere göre daha az osteolize sebep olur ve eklem artroplastisinde uygun biyomateryaller oldukları kabul edilir (Şekil 3). Konvansiyonel seramikler, fizyolojik ortamlarda yüksek mukavemet, iyi biyouyumluluk ve stabiliteleri sayesinde mükemmel biyomateryaller olarak değerlendirilir. ${ }^{[13]}$

Kalça protezlerinde alümina ara parça ile zirkonya, femoral başların uyumunun yüksek ve aşınmanın düşük olması sebebiyle tercih edilmektedir. Biyouyumluluğun yüksek ve aşınmanın düşük olmasına karşın, seramiklerin esnek olmaması ve kırılgan olması başlıca dezavantajdır. ${ }^{[13]}$

Bir diğer sık kullanılan seramikler biyo-aktif seramikler olup, bunlar kemiğin yüzeye iletişimi ve büyümesine zemin oluşturur. ${ }^{[14-16]}$
Biyo-aktif seramikler kemikte boşluk doldurucu olarak görev alır. En sık kullanılanlar, hidroksiapatit (HAp), B-trikalsiyum fosfat (b-TCP) ve bunların türevleridir. HAp, kemiğe yerleştirilmesinin ardından kemik dokuda fiziksel halini korurken, TCP tamamen çözülür. Biyo-aktif camlar ile kombine edilerek, seramiklerin biyo-uyumluluğu ve mekanik özellikleri artırılır.[11] Seramiklerin mekanik özellikleri Tablo 2'de gösterilmiştir. ${ }^{9,10]}$

\section{KALÇA PROTEZLERINDE KULLANILAN ASETABULAR KOMPONENTLER}

\section{Çimentolu Asetabular Komponentler}

Sir Charnley'in 1960’lı yıllarda geliştirdiği yüksek yoğunluklu polietilen asetabular komponentin başarılı olmasının ardından, bu alanda çalışmalar hızlanmıştır. ${ }^{[17,18]}$

Polietilen karbon fiberlerinin eklenip yüksek sıcaklık ve basınçta kristalize edilmesiyle dayanıklılığı ve aşınmaya direnci artırılmış olan yüksek molekül ağırlıklı polietilen (UHMWPE), radyasyon ve ışınlama ile çapraz bağ sayısı ve yoğunluğu artırılarak daha dayanıklı hale getirilmektedir. Bu çapraz bağ artışı aynı zamanda kııılganlığı da artırdığından, eritme yöntemiyle serbest oksijen radikalleri uzaklaştırılır ve böylece kırılganlık azaltılmaya çalışııı. ${ }^{[19,20]}$

Çimentolu asetabular komponentin çimento ile temas yüzeyini artırmak için polietilenin arkasında girintili-çıkıntılı kanallar bulunur. Bu sayede temas yüzeyi artarve rotasyon direnci de artırılmış olur. Çimentonun donma anına kadar uygun basınç sağlanması çok önemlidir. Aksi halde bu, başarısız cerrahi sonuçlara sebep olabilir. ${ }^{[19,20]}$

\section{Çimentosuz Asetabular Komponent}

Çimentosuz asetabular biyomateryaller; seramik, kobalt-krom ve alaşımları ile titanyum ve alaşımlarından

Tablo 2. Seramiklerin biyomekanik özellikleri ${ }^{[9,10]}$

\begin{tabular}{lccc}
\hline Materyal & $\begin{array}{c}\text { Sıkıştırılma } \\
\text { direnci } \\
(\mathrm{MPa})\end{array}$ & $\begin{array}{c}\text { Maksimum } \\
\text { gerilme direnci } \\
(\mathrm{MPa})\end{array}$ & $\begin{array}{c}\text { Modülüs } \\
(\mathrm{GPa})\end{array}$ \\
\hline Zirkonya & 2000 & 820 & 220 \\
Alumina & 4000 & 300 & 380 \\
Hidroksiapatit & 600 & 50 & 117 \\
\hline $\mathrm{MPa}$, mega paskal; GPa, giga paskal. & &
\end{tabular}




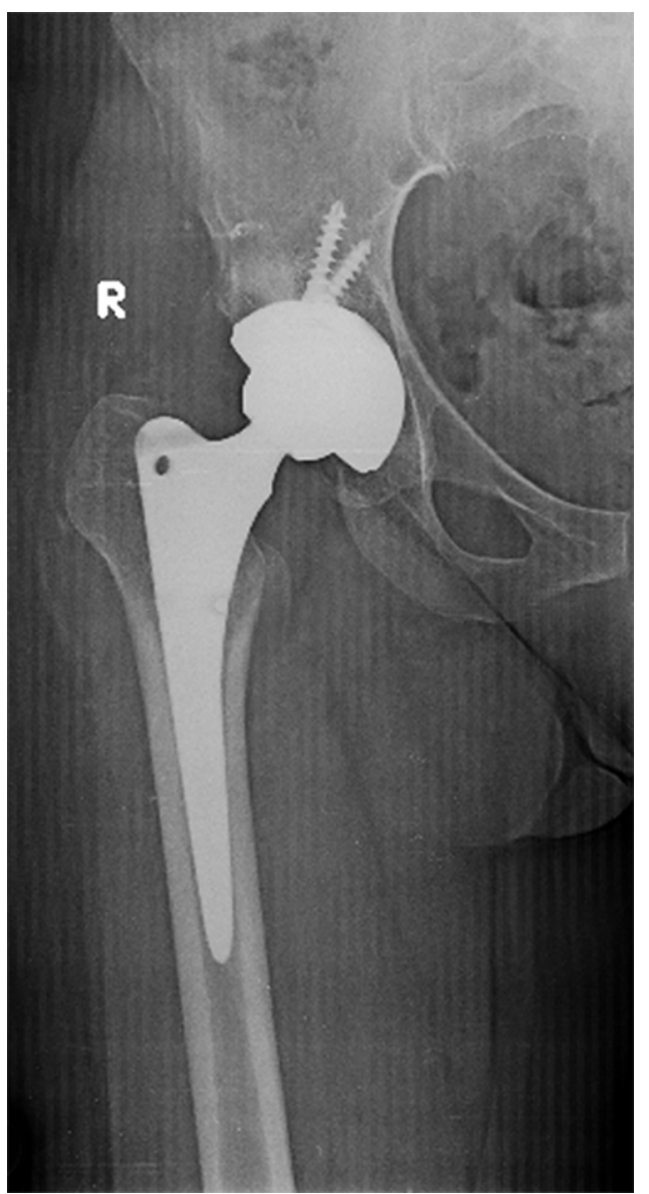

Şekil 4. Total kalça artroplastisinde kullanılan çimentosuz asetabular kap, iki adet asetabular vida ve çimentosuz femoral stem direkt grafisi.

oluşur. Teknolojik ilerlemeler ile birlikte, bu komponentlerin yüzeyleri osteo-integrasyonun güçlendirilmesi için poröz yapılmakta ya da hidroksiapatit (HA) kaplama ile kullanılmaktadır.

Hemisferik yapılı titanyum alaşımının yüzeyinin kobalt-krom ile kaplanması ile oluşan tantalyum yüksek poroziteye sahiptir. Porozitenin oluşturduğu sürtünme yüzeyi ile titanyumun osteo-indüktif özelliği sayesinde iyi bir implant kemik yapışması sağlanır. Ayrıca tantalyumun elastik modülüsü kemiğe benzer, bu da güç kalkanı etkisini azaltır. ${ }^{[21]}$

Çimentosuz asetebular komponentler, özellikle kemik kalitesi iyi olmayan hastalarda, vidalar ile tespit edilerek desteklenebilir (Şekil 4). Vida deliklerinin aşınan parçalar için bir yol oluşturacağı unutulmamalı ve mümkün olduğunca üçten fazla delik açılmamalıdır. Delik açma işleminin eksantrik olmamasına, çapına ve kalitesine çok dikkat edilmelidir. ${ }^{[22]}$
Asetabular komponent ile insert arasındaki uyum çok önemlidir. Oluşabilecek mikro-hareketler erken aşınma ile sonuçlanır. ${ }^{[23]}$

\section{Revizyon Asetabular Komponentler}

Hemisferik poröz kaplı çimentosuz asetabular komponentler, günümüzde revizyon cerrahisinde en sık kullanılan implantlardır. Kemik defektlerinde jumbo çimentosuz kaplar da sıklıkla kullanılır. Bu kapların avantajı, kemik defekti olan inferior yerine, ilium üzerine yerleştirilerek kemik defektinin by-pass edilmesidir. Ayrıca bu sayede kalça merkezi de değişmemiş olur. Ciddi asetabular kemik kaybında antiprotrusio kafesleri de kullanılabilir (Şekil 2). Bu kafesler, vida ile çevre kemiğe tutunarak stabilizasyon sağlar. ${ }^{[24]}$

\section{FEMORAL STEMLER}

\section{Çimentolu Femoral Stemler}

Çimentolu femoral stemler, günümüzde sıklıkla kemik kalitesi iyi olmayan hastalarda ya da kemik defektinden dolayı yük aktarımının daha distale taşınması gereken durumlarda kullanılmaktadır. Kemik-implant arasında basarak sıkıştırma (press-fit) gibi bir ilişki beklenmediğinden femur kanalı içinde daha az yer kaplayan ince stemler kullanılabilir. Bunun için de, çimentolu stemlerde sıklıkla elastik modülüsü yüksek ve sertliği fazla olan kobalt-krom ya da paslanmaz çelik stemler kullanilır. ${ }^{[25]}$

Konvansiyonel yakalıklı çimentolu stemler de, stemin boyun bölgesinde yüzeyinin mat veya saten özellikte olması sayesinde, stem ile kemik arasında mikro harekete izin vermeyecek şekilde implant-çimento-kemik ilişkisi sağlar. Stem ile çimento arasında oluşacak mikro-hareketler, mikro-partiküllerin kopmasına ve erken gevşemeye neden olur. İmplant uygulama başarısının en önemli noktası, kemik-implant arasındaki tespitin iyi olmasıdır. Yakalık sayesinde, çimentonun içerisine stem daha kontrollü yerleştirilir ve daha az çökme görülür. Parlak ve yakalıksız stemlerde, yüklenme sonrası stem çimento içerisine çöker (subsidence). Bu çökme, kama geometrili stemlerde dairesellere göre daha azdır. Yüzey parlaklığı sayesinde çimentonun aşınması daha az görülür. ${ }^{[26]}$

\section{Çimentosuz Femoral Stemler}

Çimentosuz femoral stemler, ister kama şeklinde isterse dairesel olsun, medüller kanalı doldurmak zorundadır. Medüller kanala basarak sıkıştırma şeklinde yerleştirilmiş yüzeyi, asetabular komponent gibi osteointegrasyonu sağlayacak porozitede olmalıdır. Bu yüzeyler, osteo-integrasyonu artıracak şekilde hidroksiapatit kaplı olabilir. ${ }^{[27]}$ 
Proksimali poröz kaplı kama tipi çimentosuz femoral stemler en yaygın kullanılanlarıdır. Proksimal tespit yetersizliklerinde, revizyon cerrahisinde sıklıkla kullanılan silindirik uzun stemlerin güç kalkanı etkisinin, kama şeklindeki stemlere göre dört kat daha fazla olduğu bildirilmiştir. ${ }^{[28]}$

\section{Revizyon Femoral Stemler}

Revizyon cerrahisinde kemik kaybı olduğu için kullanılacak biyomateryaller de bu duruma uygun olmalıdır. Kemik kaybından ötürü, çimentolu sistemlerin uzun dönem sonuçlarının daha kötü olduğu bildirilmiştir. Revizyon cerrahisinde kansellöz kemik kaybı olduğu için, kemik-çimento bileşkesinde kayma direncinin daha düşük olması beklenir. Birinci jenerasyon çimentolama tekniğinde, distal durdurucu kullanılmadığı için mekanik başarısızıı daha fazladır; bu nedenle, aseptik gevşeme daha fazla görülür. İkinci jenerasyon çimentolama tekniğinde ise distal durdurucu ve çimento tabancası kullanıldığı için daha başarılı sonuçlar elde edilmiştir. ${ }^{[24]}$

Çimentolu sistemlerin başarısızlığı yüksek olduğu için, alternatif olarak çimentosuz sistemlere yönelinmiştir. Monoblok ve proksimal poröz kaplı implantların da sonuçları, proksimal bölgede kemik kaybı olduğu için, çok başarılı değildir. Aşırı poröz kaplı stemler, proksimal bölgeyi by-pass ettiği için daha başarılıdır. Bu sistemler ile 10 yıllık başarı oranının \%95 üzeri olduğu bildirilmiştir. Proksimal kemik defekti olan hastalarda; modüler olmayan, konik tasarımlı ve titanyum femoral stemler de kullanılabilir. Titanyum, düşük elastik modülü sayesinde proksimal kemik yeniden şekillenmesine müsaade etmektedir; fakat monoblok olması sebebiyle yüksek oranda çökme gözlenmiştir. ${ }^{[24]}$

\section{KAYNAKLAR}

1. Jones LC, Hungerford DS. Cement disease. Clin Orthop Relat Res 1987;(225):192-206. Crossref

2. McKee GK, Watson-Farrar J. Replacement of Arthritic Hips By The Mckee-Farrar Prosthesis. J Bone Joint Surg Br 1966;48$\mathrm{B}(2): 245-59$. Crossref

3. Walker PS, Gold BL. The tribology (friction, lubrication and wear) of all-metal artificial hip joints 1971. Clin Orthop Relat Res 1996;329(Suppl): S4-10. Crossref

4. Christel P, Meunier A, Lee AJC. Biological and Biomechanical Performance of Biomaterials. Amsterdam, The Netherlands: Elsevier; 1997. p.81-6.

5. Huiskes R, Chao EY. A Survey of Finite Element Analysis in Orthopedic Biomechanics: The First Decade. J Biomech 1983;16(6):385-409. Crossref

6. Katti KS. Biomaterials in Total Joint Replacement. Colloids Surf B Biointerfaces 2004;39(3):133-42. Crossref

7. CharnleyJ. Arthroplasty of the Hip. A New Operation. Lancet 1961;277(7187):1129-32. Crossref
8. Szycher M; Society of Plastics Engineers. Biocompatible Polymers, Metals and Composites. Lancaster PA: Technomic Pub Co.;1983. p.1022.

9. Schmitt FO. Adventures In Molecular Biology. Ann Rev Biophys Biophys Chem 1985;14(1):1-23. Crossref

10. Ramakrishna S, Mayer J, Wintermantel E, Leong KW. Biomedical Applications of Polymer-Composite Materials: A Review. Composites Sci Tech 2001;61(9):1189-224. Crossref

11. Köse N. Ortopedide Biyomalzemeler ve İmplantlara Biyolojik Yanıt -Temel Bilimler ve Araştırma Kitabı (Korkusuz F, editör). Ankara: Totbid-Bayt; 2016. s.3-16.

12. Piconi C, Maccauro G, Muratori F, Del Prever EB. Alumina and Zirconia Ceramics in Joint Replacements. J Appl Biomater Biomech 2003;1(1):19-32. https://pubmed.ncbi.nlm.nih. gov/20803469/

13. Hulbert SF. Ceramics in Clinical Applications: Past, Present and Future. In: P. Vincenzini, editor. High Tech Ceramics. Amsterdam: Elsevier; 1987. p.189-213.

14. Wnek G, Bowlin G. Encyclopedia of Biomaterials and Biomedical Engineering, 2nd ed. Boca Raton: CRC Press; 2008.

15. Görgeç M, Öztürk I, Aksoy B, Bombacı H, editörler. Ortopedi ve Travmatolojide Biyomateryaller. İstanbul: Türk Ortopedi ve Travmatoloji Derneği; 2005.

16. Havitcioglu H. İmplantlar. İçinde: Akçalı ID, Ün K, Gülşen M, editörler. Kas İskelet Sistemi Biyomekaniği. Adana: Nobel Kitabevi; 2009. p.391-432.

17. Callaghan J, Salvati EA, Pellicci PM, Wilson PD. Ranawat CS. Results of Revision for Mechanical Failure After Cemented Total Hip Replacement, 1979 to 1982. A Two to Five-year Follow-up. J Bone Joint Surg Am 1985;67(7):1074-85. Crossref

18. Schulte KR, Callaghan JJ, Kelley SS, Johnston RC. The Outcome of Charnley Total Hip Arthroplasty with Cement After a Minimum Twenty-year Follow-up. The Results of One Surgeon. J Bone Joint Surg Am 1993;75(7):961-75. Crossref

19. Li S, Burstein AH. Ultra-High Molecular Weight Polyethylene. The Material and Its Use in Total Joint Implants. J Bone Joint Surg Am 1994;76(7):1080-90. Crossref

20. Muratoglu OK, Bragdon CR, O'Connor DO, Jasty M, Harris WH. A Novel Method of Cross-linking Ultra-high Molecularweight Polyethylene to Improve Wear, Reduce Oxidation, and Retain Mechanical Properties. Recipient of the 1999 HAP Paul Award. J Arthroplasty 2001;16(2):149-60. Crossref

21. Meneghini RM, Ford $\mathrm{KS}$, McCollough $\mathrm{CH}$, Hanssen $\mathrm{AD}$, Lewallen DG. Bone Remodeling Around Porous Metal Cementless Acetabular Components. J Arthroplasty 2010;25(5):741-7. Crossref

22. Huo MH, Stockton KG, Mont MA, Parvizi J. What's New in Total Hip Arthroplasty. J Bone Joint Surg Am 2010;92(18):2959-72. Crossref

23. Hermida JC, Bergula A, Chen P, Colwell CW, D'Lima DD. Comparison of the Wear Rates of Twenty-eight and Thirty two-millimeter Femoral Heads on Cross-linked Polyethylene Acetabular Cups in a Wear Simulator. J Bone Joint Surg Am 2003;85(12):2325-31. Crossref

24. Barrack RL, Booth REJr, Lonner JH, McCarthy, JC, Mont, MA, Rubash, HE, editors. Orthopaedic Knowledge Update. Hip and Knee Reconstruction 3. Rosemont: American Academy of Orthopaedic Surgeons; 2006. 
25. Emerson RH, Head WC, Emerson CB, Rosenfeldt W, Higgins LL. A Comparison of Cemented and Cementless Titanium Femoral Components Used for Primary Total Hip Arthroplasty: A Radiographic and Survivorship Study. J Arthroplasty 2002;17(5):584-91. Crossref

26. Carrington NC, Sierra RJ, Gie GA, Hubble MJ, Timperley AJ, Howell JR. The Exeter Universal Cemented Femoral Component at 15 to 17 years: An Update on the First 325 Hips. J Bone Joint Surg Br 2009;91-B(6):730-7. Crossref
27. Race A, Heffernan CD, Sharkey PF. The Addition of a Hydroxyapatite Coating Changes the Immediate Postoperative Stability of a Plasma-Sprayed Femoral Stem. Arthroplasty 2011;26(2):289-95. Crossref

28. Bobyn JD, Pilliar RM, Cameron HU, Weatherly GC, Kent GM. The Effect of Porous Surface Configuration on the Tensile Strength of Fixation of Implants by Bone Ingrowth. Clin Orthop Relat Res 1980;(149):291-8. https://pubmed.ncbi. nlm.nih.gov/7408314/ 